\title{
Electrochemical and Photoelectrochemical Decoloration of Amaranth Dye Azo Using Composited Dimensional Stable Anodes
}

\author{
Moisés I. Salazar-Gastélum, Edgar A. Reynoso-Soto, Shui W. Lin, Sergio Perez-Sicairos, \\ Rosa M. Félix-Navarro* \\ Ingeniería en Nanotecnología, Centro de Graduados e Investigación en Química del Instituto Tecnológico de Tijuana, Tijuana, \\ México. \\ Email: *rmfelix2003@yahoo.com.mx
}

Received November $13^{\text {th }}, 2012$; revised December $15^{\text {th }}, 2012$; accepted January $7^{\text {th }}, 2013$

\begin{abstract}
In this paper we report the results of our experimental work conducted to decoloration of a well-known highly toxic Amaranth dye by electrochemical and photoelectrochemical methods. Used throughout this investigation were two different Dimensional Stable Anode (DSA) electrodes, namely, $\mathrm{IrO}_{2}-\mathrm{Ru}_{2} \mathrm{O}-\mathrm{SnO}_{2}-\mathrm{TiO}_{2} / \mathrm{Ti}$ and $\mathrm{Ru}_{2} \mathrm{O}-\mathrm{SnO}_{2}-\mathrm{TiO}_{2} / \mathrm{Ti}$. The experimental results show that $\mathrm{IrO}_{2}-\mathrm{Ru}_{2} \mathrm{O}-\mathrm{SnO}_{2}-\mathrm{TiO}_{2} / \mathrm{Ti}$ electrode has higher performance on amaranth decoloration than $\mathrm{Ru}_{2} \mathrm{O}-\mathrm{SnO}_{2}-\mathrm{TiO}_{2} / \mathrm{Ti}$ electrode, but with the disadvantage of higher energy consumption. For higher degradation of Amaranth dye with both DSA electrodes, the process was carried out via photoelectrochemical method. Our experimental results clearly shown the decrease in absorbance of all UV-Vis peaks due to the mineralization of the azo dye; also, it was noteworthy photoelectrochemical process consumes less energy under the same experimental conditions than electrochemical process. The $\mathrm{IrO}_{2}-\mathrm{Ru}_{2} \mathrm{O}-\mathrm{SnO}_{2}-\mathrm{TiO}_{2} / \mathrm{Ti}$ electrode reaches a higher degradation degree of Amaranth solutions than $\mathrm{Ru}_{2} \mathrm{O}-\mathrm{SnO}_{2}-\mathrm{TiO}_{2} / \mathrm{Ti}$ electrode using a photoelectrochemical technique.
\end{abstract}

Keywords: Photoelectrochemical; Decoloration; DSA, Azo; Amaranth Dye

\section{Introduction}

Textile dyeing industry consumes large quantity of water and the wastewater volumes produced from different steps in dyeing is equally large to the finishing processes. The discharge of none or poorly treated textile dye wastewater into aquatic habitats is detrimental to the environment. Even though treatment methods of dye wastewater had been developed throughout the years, however the classical methods of disposal are not adequate due to the fact that partial oxidation or reduction of the chemical dyes would produce highly toxic byproducts. At the present time conventional practice of wastewater decontamination can be classified as biological [1], physical [2], chemical [3] and advanced oxidation process [4] methods. Beside these categories of treatment methods, the electrochemical methods have been proved to be very effective specifically to wastewater containing water soluble toxic inorganic and organic compounds [5, 6]; these methods are mainly characterized by being inexpensive to operate and the systems are stable during the treatment operation. For example, one of the most

${ }^{*}$ Corresponding author. common electrochemical methods employed for degradation of dissolved organic compounds in water is the indirect oxidation, wherein the degradation of the organic compound is performed by generation of oxidizing species from an anode coated with electro-catalytic material. Many materials are being employed for generation of oxidizing species, one of them is the Dimensional Stable Anodes or DSA electrodes, these electrodes are composed by a mixture of metal oxides deposited on a metallic substrate such as titanium. These kinds of DSA electrodes had been used in the degradation of some toxic organic compounds like cyanide [7], herbicides [8] and for the decoloration of different dyes [9]. DSA electrodes, composed by mixtures of Ti, Ir, Ru, Sn and/or Sb oxides, have high surface area, excellent mechanical and chemical resistance even at high current density and in strongly acid media. However, these active anodes show limited oxidation power to destroy the dyestuffs due to their low ability to generate the hydroxyl free radical $(\cdot \mathrm{OH})$.

Amaranth, also known as acid red 27, is a well-known azo dye which is widely used for coloring textile materials, paper, wood, leather, etc. For long time it was also used as coloring agent for foodstuffs like jams, jellies, 
ketchup and cake decoration, but in the last few years the carcinogenicity and other toxic effects of this dye compelled authorities for its legal prohibition in many countries. Now it is well established that a prolonged intake of Amaranth can result in tumors, allergy, respiratory problems and birth defects for the human being. Since Amaranth possesses exceptionally good solubility in water, its removal by common chemical treatments or by physical treatments like coagulation, froth floatation, etc. is not easy [10].

Semdé and coworkers reported decoloration of Amaranth dye solution employing bacteria like Clostridium perfringens; they obtained a $90 \%$ in Amaranth decoloration in 25 minutes [11].

Yang and coworkers conducted the decoloration of Amaranth by electrochemical method using a two compartment cell equipped with three electrodes, using active carbon fiber as anode and $\mathrm{Pt}$ as cathode under galvanostatic [12] and potentiostatic [13] conditions. They demonstrated the feasibility of Amaranth oxidation because its degradation by reduction is low. Also, Hattori et $a l$. worked on the electrochemical treatment in the degradation of Amaranth; they found that Amaranth was easier to be oxidized than reduced [14]. Karkmaz et al. investigated the Amaranth degradation by advanced oxidation process, using activated $\mathrm{TiO}_{2}$ powder in a photoreactor, they determined the kinetics of Amaranth degradation in this system [15].

In this work, are reported the experimental results of decoloration of Amaranth dye by photoelectrochemical and electrochemical processes. The processes involved using two different DSA electrodes with a chemical composition of $\mathrm{IrO}_{2}-\mathrm{Ru}_{2} \mathrm{O}-\mathrm{SnO}_{2}-\mathrm{TiO}_{2} / \mathrm{Ti}$ and $\mathrm{Ru}_{2} \mathrm{O}-\mathrm{SnO}_{2}$ $\mathrm{TiO}_{2} / \mathrm{Ti}$ denoted as (Ir-Ru-Sn-Ti) and (Ru-Sn-Ti) electrodes, respectively. These electrodes were shown capable of generating oxidizing species that were responsible for the decoloration of the Amaranth dye.

\section{Experimental Details}

\subsection{Reagents}

Amaranth azo dye 98\% was purchased from Sigma Aldrich. $\mathrm{NaCl} 99.4 \%, \mathrm{Na}_{2} \mathrm{SO}_{4} 99.8 \%$ and $\mathrm{KNO}_{3} 99.9 \%$ were supplied by Fermont. All chemicals used were ACS Reagent Grade. In all of the experiments, glassy carbon was used as the cathode, two DSA electrodes with the chemical compositions of Ir-Ru-Sn-Ti and Ru-Sn-Ti, were purchased from CIDETEQ, México.

\subsection{Equipment}

The electrolysis were carried out at potentiostatic conditions with a Potentiostat/Galvanostat (EG \& G PAR, model 173) coupled with a Coulometer. The reference electrode used in all experiments was a Calomel Satu- rated Electrode (CSE). The cell potentials were recorded with a digital multimeter (GW brand, model GDM-8145) connected in series. The decoloration of dyes was carried out using an electrochemical reactor as shown in Figure 1 operated in batches with stirring, the electrochemical reactor is a cylindrical quartz cell, when treatment is performed as electrochemical process this cell is placed on a stirring plate (Corning Brand, model PC-220) and when treatment is performed in photo-electrochemical process, the electrochemical reactor is placed inside a photochemical chamber Rayonet brand, model RPR100 which was modified in order to have magnetic stirring. In either case, no control over the temperature and $\mathrm{pH}$ of the solution was made. $\mathrm{pH}$ was measured with $\mathrm{pH}$ meter Corning Brand, model 430 for all samples. Decoloration rate was measured with UV-Visible spectrometer Varian brand, model Cary 100 at room temperature. Chronoamperometry tests were conducted for two DSA electrode materials as part of the physicochemical characterization, this will use a three electrode cell using such materials as work electrode, gold as counterelectrode and CSE as reference electrode, this cell was connected to a potentiostat/galvanostat Epsilon BAS. Accelerated life testing (chronopotentiometry) in order to determine the durability of the materials were conducted employing DSA electrodes as work electrode, graphite rod as counterelectrode, CSE as reference electrode and a solution of $0.5 \mathrm{M}$ $\mathrm{H}_{2} \mathrm{SO}_{4}$ as electrolyte. A HP 6038A system power supply was used. The current density applied was kept at a constant value of $1 \mathrm{~A} / \mathrm{cm}^{2}$ by the power supply system until the potential started to increase.

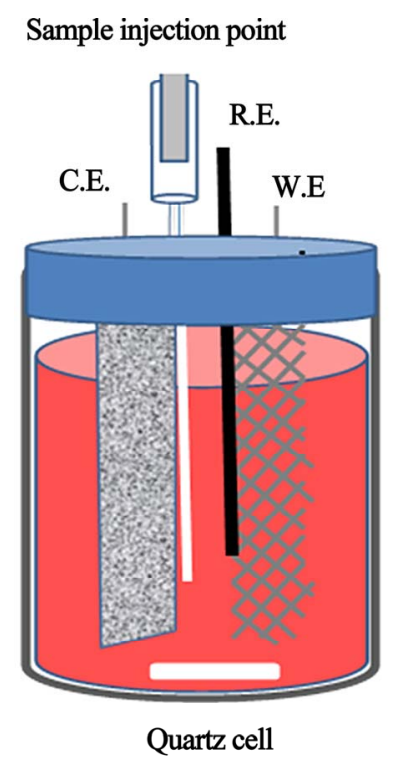

Figure 1. Schematic illustration of quartz cell used in the experiments of EC and PEC in the degradation of Amaranth: W.E. = Working Electrode, R.E. = Reference Electrode and C.E. = Counter Electrode. 


\section{Results and Discussion}

\subsection{Physicochemical Characterization of DSA Electrodes}

The DSA electrodes were analyzed by Scanning Electron Microscopy (SEM) before evaluating their performance in Amaranth decolorization experiments. The SEM micrograph of the two DSA electrodes, used for decolorizeing Amaranth dye dissolved in aqueous solution, are shown in Figure 2. These micrographs reveal an amorphous surface for both electrodes, also there was no detectable foreign material present at the surfaces of the electrodes.

Polarization curve for Ir-Ru-Sn-Ti and Ru-Sn-Ti electrodes, both having surface area of $1 \mathrm{~cm}^{2}$, is shown in Figure 3. Those curves were obtained via electrochemical technique of Chronopotentiometry with a Potentiostat/Galvanostat Epsilon BAS; while following the amperometric response of the system, the potential from Open Circuit Potential (OCP) to final potential is fixed.

As shown in Figure 3, both electrode materials are reported for the generation of $\mathrm{O}_{2}$, however Ir-Ru-Sn-Ti electrode has a higher current intensity than that of $\mathrm{Ru}-\mathrm{Sn}-\mathrm{Ti}$ electrode at the same given applied potential, this may result in a greater amount of $\mathrm{O}_{2}$ generated by this electrode material, as a matter of fact, $\mathrm{Cl}_{2}$ electrogenerated in chlorinated solutions occurs at near the same potentials as $\mathrm{O}_{2}$ generation.

\subsection{Electrochemical Treatments (EC) for the Amaranth Dye Degradation}

Amaranth is an azo dye which is characterized by having a functional group of $\mathrm{N}=\mathrm{N}$ in its chemical structure (inlet in Figure 4). Figure 4 shows the UV-Visible spectra for a $50 \mathrm{ppm}$ Amaranth in $0.1 \mathrm{M} \mathrm{NaCl}$ solution at different times of EC treatment at $1.6 \mathrm{~V}$ vs. CSE using $\mathrm{Ir}-\mathrm{Ru}-\mathrm{Sn}-\mathrm{Ti}$ as the anode. This dye has an absorption band at $521 \mathrm{~nm}$, also there are characteristic absorption peaks at 215 and $330 \mathrm{~nm}$ in the ultraviolet region due to $\pi-\pi$ electron interactions. A possible intermediate as 4aminonaphtalene sulphonic acid may exist; this intermediate would show two absorption peaks at 320 and 220 nm (not shown).

Figure 4 clearly demonstrates that decoloration of Amaranth occurs on the first 5 minutes of the experiment, however, the absorption bands at 330 and $215 \mathrm{~nm}$ persist, and this can be attributed to the slow degradation of the intermediates in the solution. After 30 minutes the absorption band at $330 \mathrm{~nm}$ has disappeared and only persist the absorption band at $215 \mathrm{~nm}, 2$ hours of electrochemical process was not sufficient, due to remains a small absorption band at $215 \mathrm{~nm}$. The electrochemical experi-
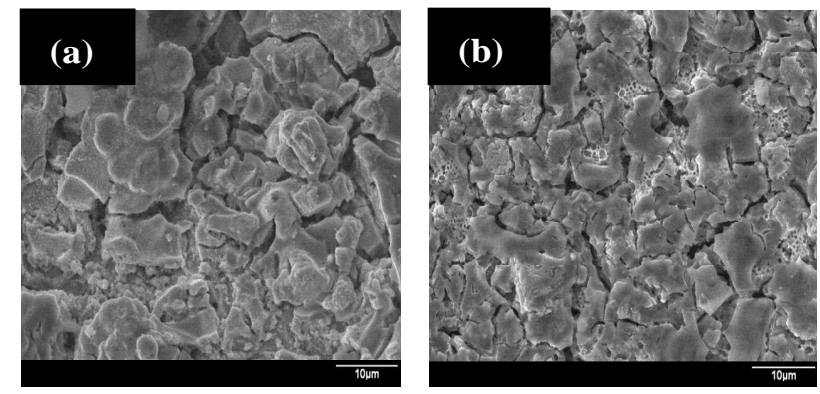

Figure 2. SEM micrographs of the surfaces of DSA electrodes: (a) $\mathrm{IrO}_{2}-\mathrm{Ru}_{2} \mathrm{O}-\mathrm{SnO}_{2}-\mathrm{TiO}_{2} / \mathrm{Ti}$ and (b) $\mathrm{Ru}_{2} \mathrm{O}-\mathrm{SnO}_{2}$ $\mathrm{TiO}_{2} / \mathrm{Ti}$.

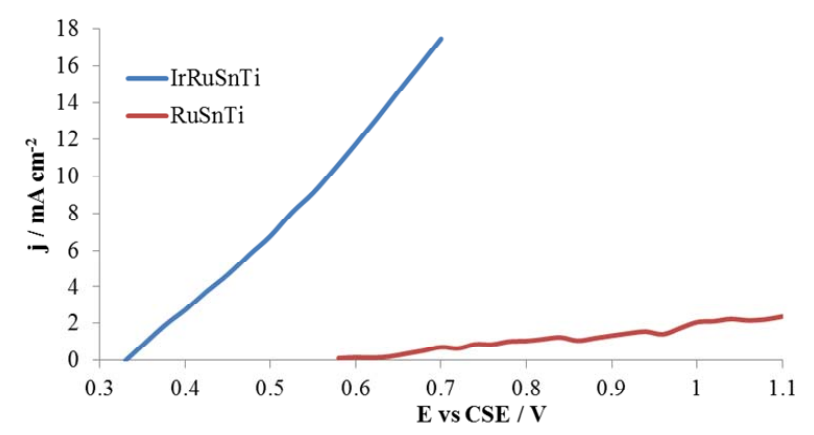

Figure 3. Polarization curves for (a) $\mathrm{IrO}_{2}-\mathrm{Ru}_{2} \mathrm{O}-\mathrm{SnO}_{2}$ $\mathrm{TiO}_{2} / \mathrm{Ti}$ and (b) $\mathrm{Ru}_{2} \mathrm{O}-\mathrm{SnO}_{2}-\mathrm{TiO}_{2} / \mathrm{Ti}$ DSA electrodes in a $0.25 \mathrm{M} \mathrm{NaCl}$ solution and at a sampling time interval of 10 ms.

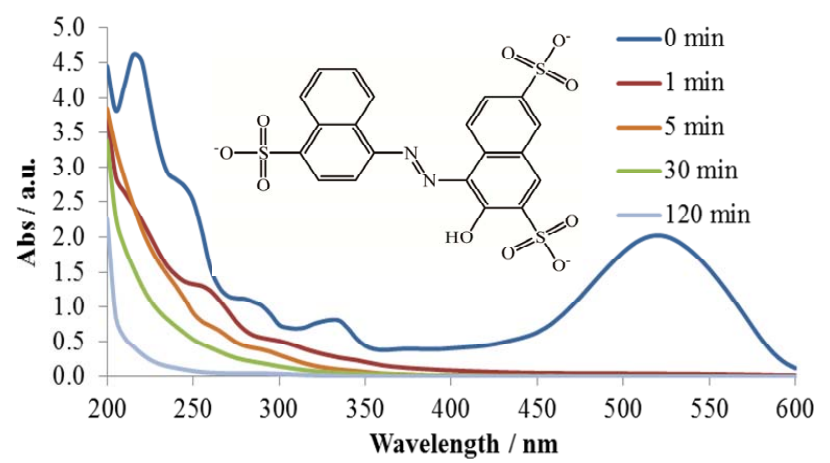

Figure 4. UV-Visible spectrum of a $50 \mathrm{ppm}$ of Amaranth in $0.1 \mathrm{M} \mathrm{NaCl}$ solution at different times of EC treatments for $\mathrm{IrO}_{2}-\mathrm{Ru}_{2} \mathrm{O}-\mathrm{SnO}_{2}-\mathrm{TiO}_{2} / \mathrm{Ti}$ at $1.6 \mathrm{~V}$ vs. CSE, inset: chemical structure of Amaranth.

ments for Amaranth dye degradation were performed in potentiostatic mode using two different working DSA electrodes namely Ir-Ru-Sn-Ti and Ru-Sn-Ti.

In this work, decolorations of different Amaranth aqueous solutions were carried out in electrolyte media such as $\mathrm{KNO}_{3}, \mathrm{Na}_{2} \mathrm{SO}_{4}$ and $\mathrm{NaCl}$. Our experimental results reveal that only the electrolyte solution containing $\mathrm{NaCl}$ could lead to complete decoloration and a less energy consumption; this is in agreement with the works by 
Cases et al. [16]. Composite DSA electrodes perform well in decoloration of azo dye in chlorinated media, because it is easy to produce reactive chlorine species, this may due to the fact that the hypochlorite ion so generated would be used for the indirect electro oxidation process [16]. Some of the reactions that may occur in chlorinated media are;

$$
\begin{gathered}
2 \mathrm{Cl}^{-} \rightarrow \mathrm{Cl}_{2}+2 e^{-} \\
\mathrm{Cl}_{2(\text { aq) }}+\mathrm{Cl} \rightarrow \mathrm{Cl}_{3} \\
\mathrm{Cl}_{2(\mathrm{aq})}+\mathrm{H}_{2} \mathrm{O} \rightarrow \mathrm{HClO}+\mathrm{H}+\mathrm{Cl} \\
\mathrm{HClO} \rightarrow \mathrm{H}^{+}+\mathrm{ClO}^{-} \\
\mathrm{ClO}^{-}+D y e \rightarrow \mathrm{CO}_{2}+\mathrm{H}_{2} \mathrm{O}+\mathrm{Cl}^{-}
\end{gathered}
$$

The degradation of the Amaranth experiments were carried out in a single compartment electroreactor and the $\mathrm{pH}$ range of the samples were 6 to 8 , it is suspected that the species responsible for most of the degradation of Amaranth is the Hypochlorite ion; in other words the indirect oxidation of the Amaranth plays an important role in the over-all process of the decoloration. All experiments were done using aqueous solution containing initial concentration of Amaranth at $50 \mathrm{ppm}$ with $0.25 \mathrm{M}$ of $\mathrm{NaCl}$ at $\mathrm{pH} \mathrm{7}$, the electrolysis process was performed at 1.5, 1.6 and 1.7 V for Ir-Ru-Sn-Ti electrode, while for the $\mathrm{Ru}-\mathrm{Sn}$-Ti electrode experiments were performed at $1.3,1.4,1.5$ and $1.6 \mathrm{~V}$.

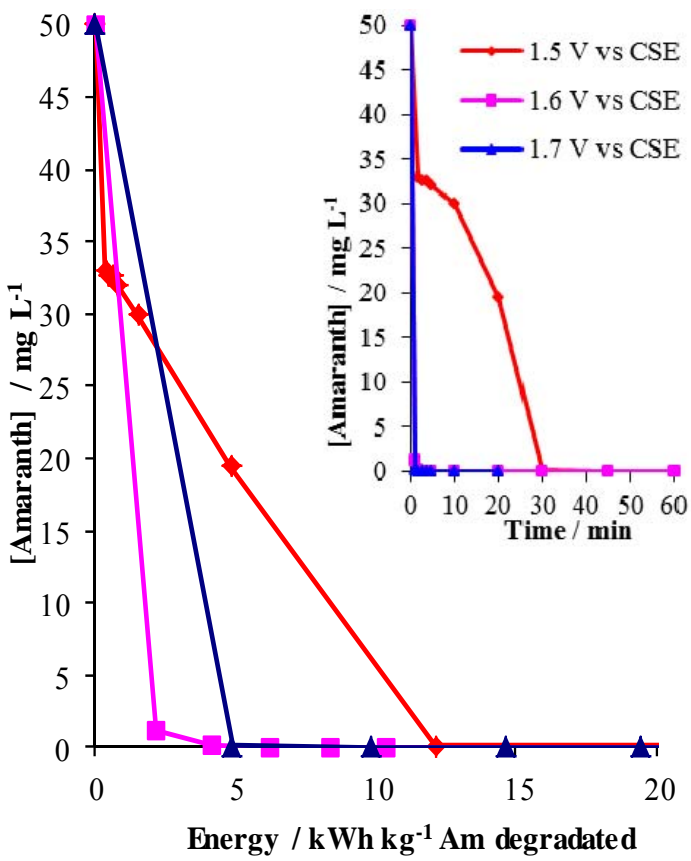

(a)
Numerous experiments were carried out to determine the appropriate potential for the degradation of Amaranth, the experimental results of the energy consumption and the time required for degradation a $500 \mathrm{~mL}$ aqueous solution containing $50 \mathrm{ppm}$ in Amaranth and $0.25 \mathrm{M} \mathrm{NaCl}$ at different potentials for both DSA electrodes are shown in Figure 5. The experimental results indicate that there is no significant dependency of the degradation of Amaranth on the applied potential, because all experiments lead to decoloration; however the decoloration times at $1.6 \mathrm{~V}$ and $1.7 \mathrm{~V}$ were observed to be shorter in compareson to $1.5 \mathrm{~V}$ when Ir-Ru-Sn-Ti electrode was used, the energy consumption at $1.6 \mathrm{~V}$ was slightly lower compared to other applied potentials. For Ru-Sn-Ti electrode, the decoloration times at $1.4 \mathrm{~V}, 1.5 \mathrm{~V}$ and $1.6 \mathrm{~V}$ were shorter and had lower energy consumption compared with $1.3 \mathrm{~V}$. Based on these experimental results, $1.4 \mathrm{~V}$ was chosen for both DSA electrodes for the benefit of lower energy consumption.

The effect of the concentration of $\mathrm{NaCl}$ on the decoloration of Amaranth for both DSA electrodes is shown in Figure 6; at almost the same time interval, the power consumption for solutions containing 0.10 and $0.25 \mathrm{M}$ in $\mathrm{NaCl}$ is the same, therefore for most of this work, $0.10 \mathrm{M}$ $\mathrm{NaCl}$ was used in the reaction solution.

Table 1 summarizes the energy consumption in each experiment for both DSA electrodes in the process of decolorization of Amaranth; for Ir-Ru-Sn-Ti electrode, the electrolysis time was 4 minutes, while for $\mathrm{Ru}-\mathrm{Sn}-\mathrm{Ti}$

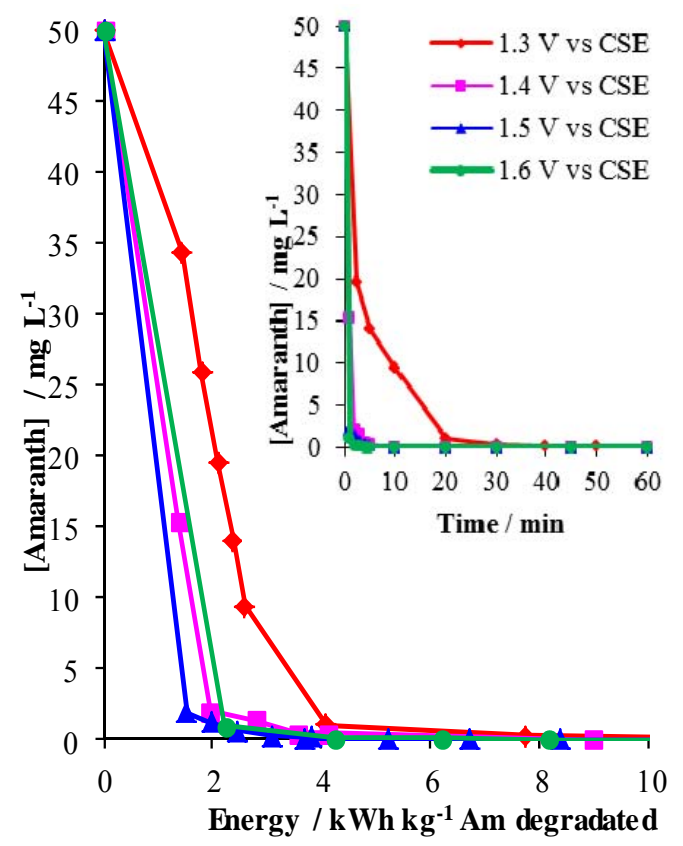

(b)

Figure 5. Amaranth concentration vs. energy consumption for different applied potentials, inset: Amaranth concentration vs. time for (a) Ir-Ru-Sn-Ti and (b) Ru-Sn-Ti electrodes. 


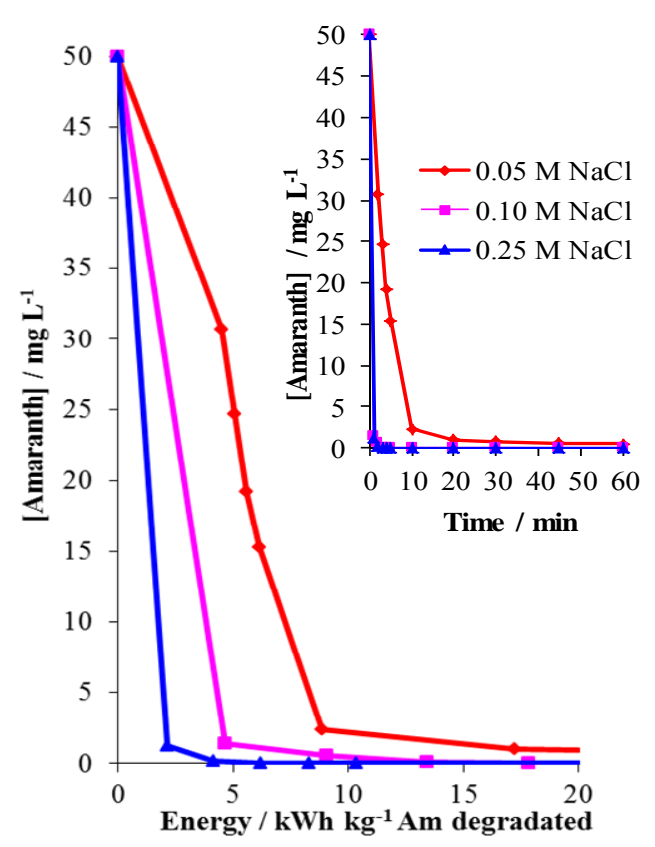

(a)

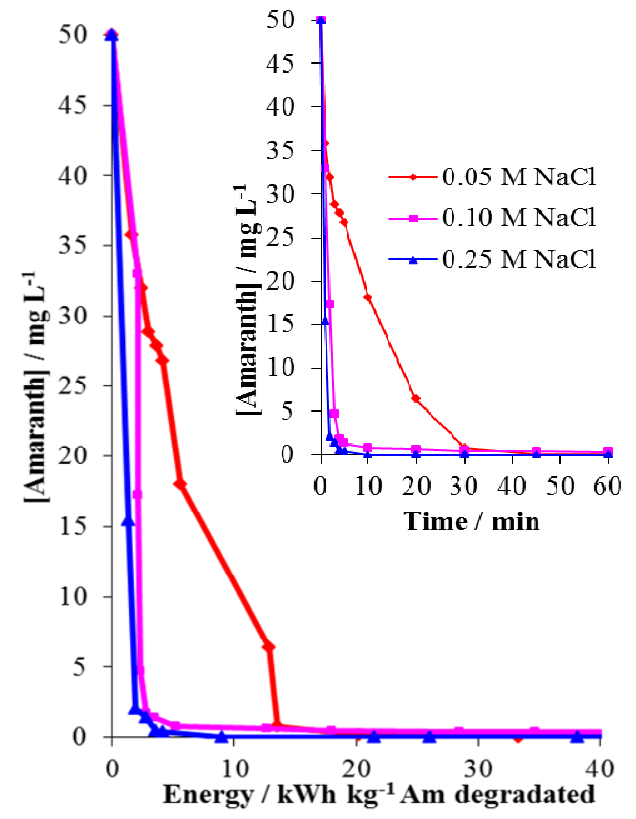

(b)

Figure 6. Energy consumption vs Amaranth concentration for different electrolyte concentration, inset: Amaranth concentration vs time for (a) Ir-Ru-Sn-Ti and (b) Ru-Sn-Ti electrodes.

Table 1. Energy consumption for electrochemical treatment in both DSA electrodes.

\begin{tabular}{ccccc}
\hline Electrode & $\begin{array}{c}\text { Potential } \\
\text { vs CSE (V) }\end{array}$ & {$[\mathrm{NaCl}]$} & $\begin{array}{c}\text { Energy } \\
\text { Consumption \% Degradation } \\
\left(\mathrm{kW} \cdot \mathrm{h} \cdot \mathrm{kg}^{-1}\right)\end{array}$ \\
\hline $\begin{array}{c}\text { Ir-Ru-Sn-Ti } \\
\text { Ru-Sn-Ti }\end{array}$ & 1.6 & $0.1 \mathrm{M}$ & 17.84 & 100 \\
& 1.4 & $0.1 \mathrm{M}$ & 17.97 & 99.06 \\
\hline
\end{tabular}

electrode, the operation time was 30 minutes.

For the purpose of determining the order of the reaction kinetics, dye decoloration experiments were conducted using the UV-visible spectrometer, with fiber optic attachment, to measure the decrease of the absorption peak at $\lambda_{\max }=520 \mathrm{~nm}$ of a solution containing 50 ppm in Amaranth and $0.10 \mathrm{M}$ in $\mathrm{NaCl}$ at an applied voltage 1.6 V vs. CSE Reference Electrode and using Ir-Ru-Sn-Ti as the anode.

As indicated in Figure 7 that the best fit reaction kinetics order is the first order and Table 2 specifies the parameters for each reaction order. This result is similar to the reaction order for another azo dye reactive orange 4 [16].

\subsection{Photoelectrochemical Treatments (PEC)}

Once the best operation conditions of the electrochemical treatment alone were selected, then the experimental works of electrochemical treatment was carried out with the enhancement of the photoelectrochemical treatment.
Table 2. Energy consumption for electrochemical treatment in both DSA electrodes.

\begin{tabular}{ccc}
\hline Reaction order & $k_{\text {app }}$ & $R^{2}$ \\
\hline 0 & $4 \times 10^{-5}$ & 0.9756 \\
1 & $9 \times 10^{-5}$ & 0.9929 \\
2 & $2.58 \times 10^{-5}$ & 0.9223 \\
\hline
\end{tabular}

The methodology of this work was similar to that of the electrochemical treatment works, except that the quartz cell was introduced into a reaction chamber; Photochemical Rayonet Model RPR 100 with 16 RPR-3500 lamps emitting radiation in the range between 300 and $400 \mathrm{~nm}$ and having a maximum emission at $350 \mathrm{~nm}$. It is important to mention that the camera was equipped with a magnetic stirrer and a temperature control which was set approximately at $35^{\circ} \mathrm{C}$ during the experimental runs.

It can be seen from Figure 8 that in both spectra ((a) and (b)), there is a noticeable decrease in the absorbance when the degradation of Amaranth is carried out by photoelectrochemical treatment method, also it reveals that there was no degradation of Amaranth when photochemical experiment was carried out alone. However, when coupled electrochemical and photochemical processes, there was a greater decrease of the signals in the UV region; this might be due to the generation of intermediate species like $\cdot \mathrm{OH}$ for both composite electrodes according to the following scheme [17]. 


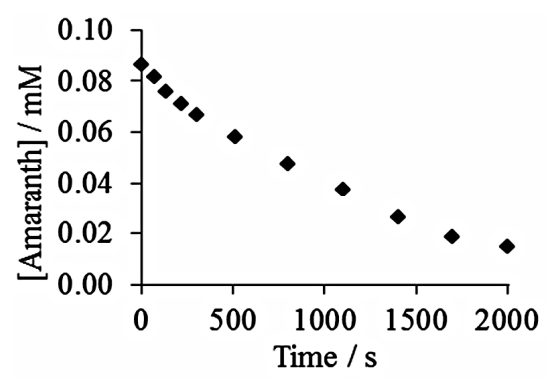

(a)

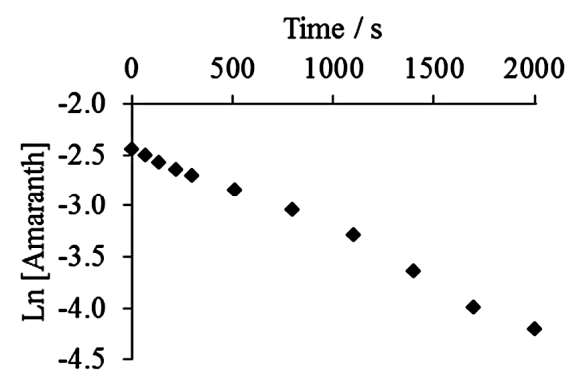

(b)

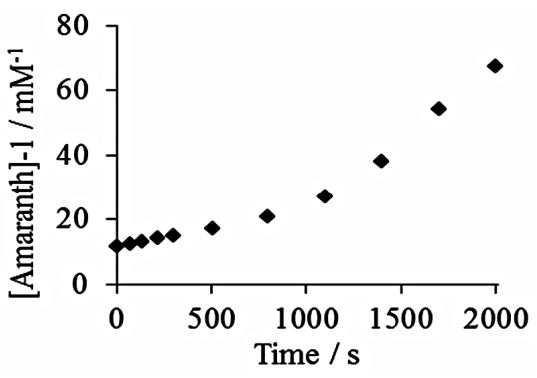

(c)

Figure 7. Reaction order for Amaranth decoloration using anode Ir-Ru-Sn-Ti at $1.6 \mathrm{~V}$ for a solution containing 50 ppm Amaranth and $0.1 \mathrm{M} \mathrm{NaCl}$. (a) Zero order reaction, (b) first order reaction and (c) second order reaction.

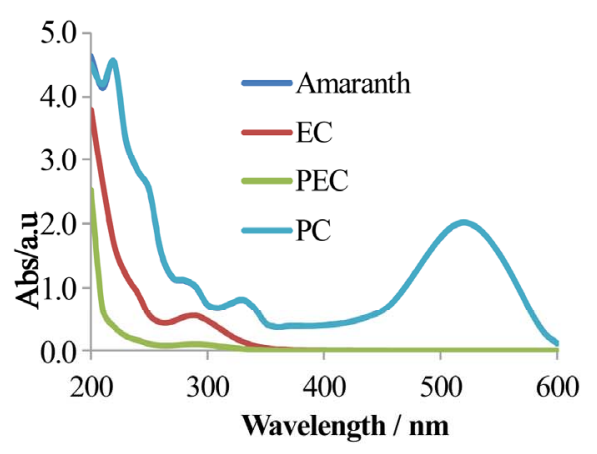

(a)

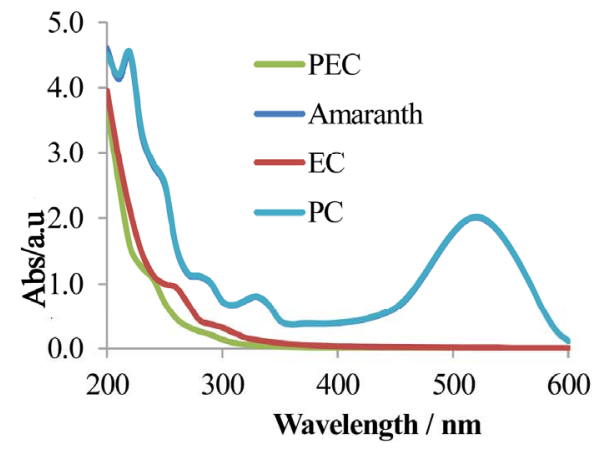

(b)

Figure 8. UV spectra after 2 h of Electrochemical (EC), Photoelectrochemical (PEC) and Photochemical (PC) treatments for Amaranth degradation using anodes of Ir-Ru-Sn-Ti (a) and Ru-Sn-Ti (b).

$$
\begin{gathered}
e^{-}+\mathrm{O}_{2} \rightarrow \mathrm{O}_{2}^{\bullet-} \\
2 \mathrm{O}_{2}^{\bullet-}+2 \mathrm{H}_{2} \mathrm{O} \rightarrow 2 \bullet \mathrm{OH}+2 \mathrm{OH}^{-}+\mathrm{O}_{2}
\end{gathered}
$$

Also, Zanoni et al. reported the increase in concentration of electro-generated active chlorine at $\mathrm{TiO}_{2}$ anode under UV illumination [18].

The formation of $\cdot \mathrm{OH}$ and the increase in concentration of active chlorine are two explanations for the better performance of PEC treatment than EC treatment.

The energy consumptions for degradation of azo dye Amaranth by electrochemical and photoelectrochemical treatment methods using Ir-Ru-Sn-Ti and Ru-Sn-Ti electrodes are summarized in Table 3.

The energy consumptions by electrochemical treatment were calculated from the current-voltage loads, while the energy consumptions for Photoelectrochemical treatments were the energy consumed by electrochemical treatment plus the radiated energy; the radiated energy was calculated with the equation shown below;

$$
E_{\text {rad }}=16 \theta A t
$$

Here 16 is the number of lamps used, $A$ is the exposed area of the lamp, $\theta$ is the radiant energy per unit area of the lamp; this information was provided by the equip-
Table 3. Energy consumption for degradation of Amaranth by Electrochemical (EC) and Photoelectrochemical (PEC) treatment methods using Ir-Ru-Sn-Ti and Ru-Sn-Ti electrodes for a 2 hours processing time.

\begin{tabular}{lcc}
\hline \multicolumn{1}{c}{ Experimental Conditions } & $\begin{array}{c}\text { Treatment } \\
\text { Method }\end{array}$ & $\begin{array}{c}\text { Energy } \\
\text { Consumption } \\
\left(\mathrm{kW} \cdot \mathrm{h} \cdot \mathrm{kg}^{-1}\right)\end{array}$ \\
\hline $\begin{array}{l}\text { CSE with Ir-Ru-Sn-Ti } \\
\text { CSEm Amaranth 0.1 M NaCl 1.6 V vs }\end{array}$ & EC & 461.6 \\
& PEC & 277.9 \\
$\begin{array}{l}\text { CSE ppm Amaranth 0.1 M NaCl 1.4 V vs } \\
\text { CSE Rn-Ti }\end{array}$ & EC & 72.7 \\
\hline
\end{tabular}

ment manufacturer and $t$ is the time of reactor in operation.

The results of Accelerated life tests are shown in Figure 9. In this Figure, it's possible to observe that under the same testing conditions described above, Ir-Ru-Sn-Ti anode is stable after more than 100 hours of operation, while Ru-Sn-Ti barely reaches 5 hours; it is noteworthy that after 100 hours of operation, the electrode Ir-Ru-SnTi was still working well. 


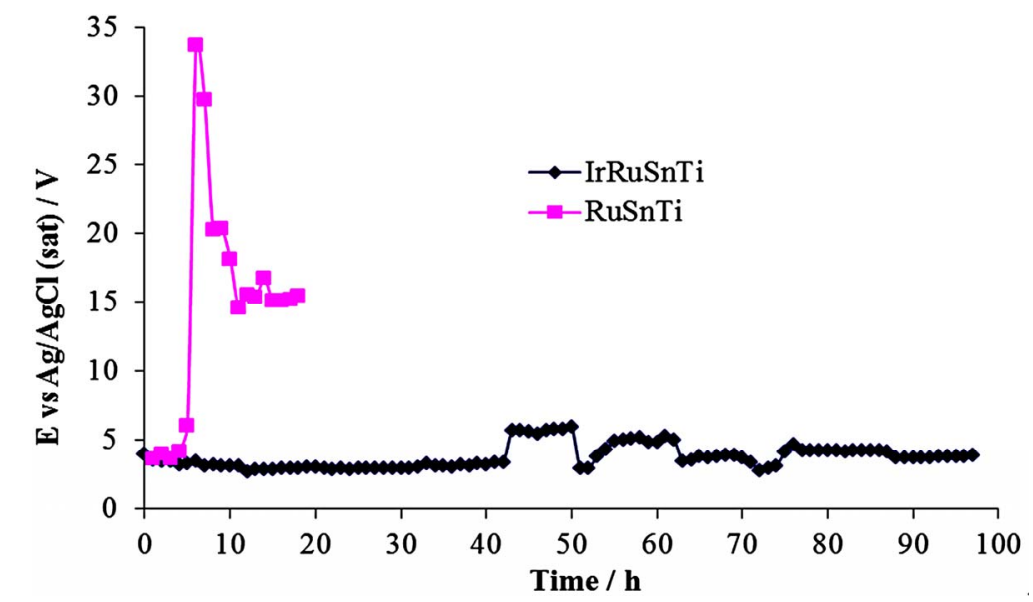

Figure 9. Chronopotentiometric plots for Ir-Ru-Sn-Ti and Ru-Sn-Ti anodes immersed in a $0.5 \mathrm{M} \mathrm{H}_{2} \mathrm{SO}_{4}$ solution.

\section{Conclusions}

Electrochemical (EC) treatment experiments for Amaranth degradation were performed to study the effects of the applied potential, the concentration of $\mathrm{NaCl}$ and the type of DSA electrodes used. DSA electrodes of $\mathrm{IrO}_{2}$ $\mathrm{Ru}_{2} \mathrm{O}-\mathrm{SnO}_{2}-\mathrm{TiO}_{2} / \mathrm{Ti}$ and $\mathrm{Ru}_{2} \mathrm{O}-\mathrm{SnO}_{2}-\mathrm{TiO}_{2} / \mathrm{Ti}$ were characterized by SEM and electrochemical techniques (chronoamperometry). Results indicated that both electrodes performed equally well in aqueous solution containing $\mathrm{NaCl}$; because electrodes are capable of generating hypochlorite ions at the $\mathrm{pH}$ range of $6-8$, since the hypochlorite ion is a strong oxidant; it is used to degrade the Amaranth in the solution [16]. However there was no clear trend showing the effect for the selected applied potential in this work.

Under the best experimental conditions for EC treatment method of degrading Amaranth, it was determined that Ir-Ru-Sn-Ti composite electrode performed better than that of Ru-Sn-Ti electrode. The reaction follows a first order kinetics.

Employing the best electrochemical treatment conditions for both electrodes and coupling with the UV radiation, we observed that there was a decrease in the signals from the UV region in addition to the disappearance of the signal associated with Amaranth, this indicates that there is a greater degree of degradation of the dye compared with electrochemical treatment alone.

In both EC and PEC treatment processes Ir-Ru-Sn-Ti yields a higher degree of degradation of Amaranth than that of Ru-Sn-Ti electrode, however, Ir-Ru-Sn-Ti had bigger energy consumption than Ru-Sn-Ti electrode, this is consistent with the results of the polarization curve; it is noticeable that Ir-Ru-Sn-Ti electrode has a capacity to withstand higher current density than Ru-Sn-Ti electrode before reaching the saturation point. Also, we calculated the energy consumption for photoelectrochemical treatment; it shows that the energy consumptions were smal- ler in comparison with the energy consumptions by the electrochemical treatment; this is probably due to the generation of $\bullet \mathrm{OH}$ [17] and the increase in $\mathrm{Cl}_{2}$ concentration in PEC treatment process [18]. Finally, we made accelerated life test, where Ir-Ru-Sn-Ti showed much greater durability compared to Ru-Sn-Ti.

\section{Acknowledgements}

Authors would like to take this opportunity to thank the Centro de Nanociencias y Nanotecnologia of UNAM for technical support for this investigation, special thanks to Ing. Israel Gradilla. M. I. Salazar-Gastélum is grateful to CONACyT for providing the scholarship for his doctoral thesis research.

\section{REFERENCES}

[1] C. Cripps, J. A. Bumpus and S. D. Aust, "Biodegradation of Azo and Heterocyclic Dyes by Phanerochaete Chrysosporium," Applied and Environmental Microbiology, Vol. 56, No. 4, 1990, pp. 1114-1118.

[2] G. Centi, A. Grande and S. Perathoner, "Catalytic Conversion of MTBE to Biodegradable Chemicals in Contaminated Water," Catalysis Today, Vol. 75, No. 1-4, 2002, pp. 69-76. doi:10.1016/S0920-5861(02)00046-9

[3] K. Huang, R. C. Couttenye and G. E. Hoag, "Kinetics of Heat-Assisted Persulfate Oxidation of Methyl Tert-Butyl Ether (MTBE)," Chemosphere, Vol. 49, No. 4, 2002, pp. 413-420. doi:10.1016/S0045-6535(02)00330-2

[4] N. Daneshvar, S. Aber, V. Vatanpour and M. H. Rasoulifard, "Electro-Fenton Treatment of Dye Solution Containing Orange II: Influence of Operational Parameters," Journal of Electroanalytical Chemistry, Vol. 615, No. 2, 2008, pp. 165-174. doi:10.1016/j.jelechem.2007.12.005

[5] N. Daneshvar, H. Ashassi-Sorkhabi and M. B. Kasiri, "Decolorization of Dye Solution Containing Acid Red 14 by Electrocoagulation with a Comparative Investigation of Different Electrode Conections," Journal of Hazardous 
Materials, Vol. 112, No. 1-2, 2004, pp. 55-62.

doi:10.1016/j.jhazmat.2004.03.021

[6] M. F. Elahmadi, N. Bensalah and A. Gadri, "Treatment of Aqueous Wastes Contaminated with Congo Red Dye by Electrochemical Oxidation and Ozonation Processes," Journal of Hazardous Materials, Vol. 168, No. 2-3, 2009, pp. 1163-1169. doi:10.1016/j.jhazmat.2009.02.139

[7] M. R. V. Lanza and R. Bertazzoli, "Cyanide Oxidation from Wastewater in a Flow Electrochemical Reactor," Industrial \& Engineering Chemistry Research, Vol. 41, No. 1, 2002, pp. 22-26. doi:10.1021/ie010363n

[8] G. R. P. Malpass, D. W. Miwa, A. C. P. Miwa, S. A. S. Machado and A. J. Motheo, "Photo-Assisted Electrochemical Oxidation of Atrazine on a Comercial Ti/Ru0.3Ti0.7O2 DSA Electrode," Environmental Science \& Technology, Vol. 41, No. 20, 2007, pp. 7120-7125. doi:10.1021/es070798n

[9] M. Panizza and G. Cerisola, "Electrocatalytic Materials for the Electrochemical Oxidation of Synthetic Dyes," Applied Catalysis B, Vol. 75, No. 1-2, 2007, pp. 95-101. doi:10.1016/i.apcatb.2007.04.001

[10] V. K. Gupta, R. Jain, A. Mittal, T. A. Saleh, A. Nayak, S. Agarwal and S. Sikarwar, "Photo-Catalytic Degradation of Toxic Dye Amaranth on $\mathrm{TiO}_{2} / \mathrm{UV}$ in Aqueous Suspensions," Materials Science and Engineering: $C$, Vol. 32, No. 1, 2012, pp. 12-17. doi:10.1016/j.msec.2011.08.018

[11] R. Semdé, D. Pierre, G. Geuskens, M. Devleeschouwer and A. J. Moës, "Study of Some Important Factors Involved in Azo Derivative Reduction by Clostridium Perfringens," International Journal of Pharmaceutics, Vol. 161, No. 1, 1998, pp. 45-54. doi:10.1016/S0378-5173(97)00327-X

[12] L. Fan, Y. Zhou, W. Yang, G. Chen and F. Yang, "Electrochemical Degradation of Amaranth Aqueous Solution on ACF," Journal of Hazardous Materials, Vol. 137, No.
2, 2006, pp. 1182-1188. doi:10.1016/j.jhazmat.2006.04.008

[13] L. Fan, Y. Zhou, W. Yang, G. Chen and F. Yang, "Electrochemical Degradation of Aqueous Solution of Amaranth Azo Dye on ACF under Potentiostatic Model," Dyes and Pigments, Vol. 76, No. 2, 2008, pp. 440-446. doi:10.1016/j.dyepig.2006.09.013

[14] S. Hattori, M. Doi, E. Takahashi, T. Kurosu, M. Nara, S. Nakamatsu, Y. Nishiki, T. Furuta and M. Iida, "Electrolytic Decomposition of Amaranth Dyestuff Using Diamond Electrodes," Journal of Applied Electrochemistry, Vol. 33, No. 1, 2003, pp. 85-91. doi:10.1023/A:1022945714152

[15] M. Karkmaz, E. Puzenat, C. Guillard and J. M. Herrmann, "Photocatalytic Degradation of the Alimentary Azo Dye Amaranth Mineralization of the Azo Group to Nitrogen," Applied Catalysis B, Vol. 51, No. 3, 2004, pp. 183-194. doi:10.1016/j.apcatb.2004.02.009

[16] A. I. del Rio, J. Bonastre, J. Molina and F. Cases, "Influence of Electrochemical Reduction and Oxidation Processes on the Decolourisation and Degradation of C. I. Reactive Orange 4 Solutions," Chemosphere, Vol. 75, No. 10, 2009, pp. 1329-1337. doi:10.1016/j.chemosphere.2009.02.063

[17] S. A. V. Eremia, D. Chevalier-Lucia, G. Radu and J. Marty, "Optimization of Hydroxyl Radical Formation Using $\mathrm{TiO}_{2}$ as Photocatalyst by Response Surface Methodology," Talanta, Vol. 77, No. 2, 2008, pp. 858-862. doi:10.1016/j.talanta.2008.07.056

[18] M. V. B. Zanoni, J. J. Sene, H. Selcuk and M. A. Anderson, "Photoelectrocatalytic Production of Chlorine on Nanocrystalline Titanium Dioxide Thin Film Electrode," Environmental Science \& Technology, Vol. 38, No. 11, 2004, pp. 3203-3208. doi:10.1021/es0347080 